\title{
Application of HPLC to Characterization and Control of Individual Acids in Apple Extracts and Ciders
}

\author{
D. Blanco Gomis ${ }^{1 *} /$ M.J. Morán Gutiérrez ${ }^{1}$ / M. D. Gutiérrez Alvarez / J.J. Mangas Alonso² \\ ${ }^{1}$ Departamento de Quimica Fisica y Analitica, Facultad de Quimica, Universidad de Oviedo, Spain. \\ ${ }^{2}$ Centro de Experimentación Agraria, Consejeria de Agricultura y Pesca del Principado de Asturias, Villaviciosa, Spain.
}

\section{Key Words \\ Column Liquid Chromatography \\ Organic acids \\ Apple extracts}

\section{Summary}

Three HPLC methods have been tested in order to compare their separation of apple and cider organic acids. Optimum results for simultaneous determination of malic, citric, quinic, succinic, lactic and shikimic acids have been obtained using an RP-18 column with phosphate buffer as the mobile phase.

This method was applied to organic acids monitoring during the ripening of apples and throughout the fermentation process. After filtration and degasification the organic acids in the sample were separated, and quantified by using a diode array detector.

Recovery studies show good results for all solutes $(88 \%-106 \%)$. The coefficients of variation show excellent precision (5\%).

\section{Introduction}

Carboxylic acids are important constituents in many foods, either present in the raw material as in apples and in apple juice or as a result of fermentative processes as in cider. Their concentration determines $\mathrm{pH}$ and may affect the flavour and taste of the cider and susceptibility to microbial spoilage.

The nature of the processes carried out in the making of cider is affected by the quantity and the kind of acids present in the apples. For example, the concentration of malic and quinic acid in ripening apples is an important factor in determining the time of harvest because their concentration decreases during ripening. The ciders manufactured from the early apples where there is a high concentration of these two acids have a fresh green taste. Furthermore, these acids are metabolized by the lactique bacteria so that great decrease or absence of malic acid and the presence of lactic acid in a cider indicates that a secondary bacterial fermentation (malolactic fermentation) has occurred, confer- ring microbial stability on the cider and a less marked taste. Citric acid is metabolized to acetic acid and the shikimic and quinic acids are transformed into single phenols (cathecol, ethylcathecol) and other compounds [1]. Finally, the enzymatic activity and the chemical alterations are also influenced by the acidity.

Because carboxylic acids occur in natural products as mixtures with similar chemical properties the estimation of any particular acid normally requires a separation step before quantification. Organic acids in foods and beverages may be analyzed by several different chromatographic techniques. The applicability of a specific method to routine analytical practice is determined by the simplicity and rapidity of the determination, including the sample preparation.

Gas chromatography [2] has been used for the determination of organic acids. However, since most organic acids are not sufficiently volatile, the preparation of suitable volatile derivatives is required (the conversion of carboxylic groups into methyl esters or trimethyisilyl esters) and these chromatographic technique does not meet the simplicity requirement because of the complicated preparation of samples.

High performance liquid chromatography (HPLC) affords a rapid and simple technique for analyzing certain mixtures of organic acids. Many analytical methods have been reported for the separation and determination of organic acids [3-9]. According to some authors [10], four main methods are commonly used, namely ion-exchange chromatography, ionexclusion chromatography, ion-pair chromatography and reversed-phase chromatography.

The choice of method depends on the nature of the acids to be analyzed and of the matrix in which they are present as well as their relative concentration in the sample.

This paper is concerned with the application of HPLC methods to the organic acids monitored in the course of the ripening of apples, and the fermentation of ciders. It describes a rapid procedure for quantifying malic, quinic, citric and shikimic acids in apple extracts using a column packed with octadecyl silica $(\mathrm{C}-18)$ with a phosphate buffer as eluent. This method has also been used for the determination of the compounds, mentioned above, and of lactic and succinic acids which are formed in the course of the malolactic fermentation and as sub-product of the glyceropyruvic fermentation, in apple juices and ciders [11]. Some alternative column packings for organic acid analysis are also presented. 
Typical analytical results are reported for five varieties of apples in different stages of ripening and two apple juices in several stages of fermentation.

\section{Experimental}

A LKB (Bromma, Sweden) Liquid Chromatograph was used. The chromatograph was equipped with a Model 2150 pump, a Rheodyne Model 7125 injection valve equipped with a $20 \mu l$ loop, a LKB Model 2140 rapid spectral detector and an IBM data station. Column effluents were monitored at a wavelength of $206 \mathrm{~nm}$. Analyses were performed isocratically at a flow rate of $0.5 \mathrm{ml} / \mathrm{min}$ and a temperature of $25^{\circ} \mathrm{C}$. Quantification was based on peak area measurements.

The HPLC columns were a $200 \times 7.8 \mathrm{~mm}$ i.d. (Interaction $10 N-300)$ packed with a cation exchange resin in the hydrogen ion form; a $250 \times 4 \mathrm{~mm}$ i.d. $5 \mu \mathrm{m}$ Spherisorb $\mathrm{NH}_{2}$; and a $250 \times 4 \mathrm{~mm}$ i.d. $5 \mu \mathrm{m}$ Spherisorb ODS-2 (C 18).

Column temperature was raised by placing the columns in a thermostat regulated by a circulating water bath.

The mobile phases were buffer solutions consisting of $10^{-2} \mathrm{M}$ or $7.510^{-2} \mathrm{M}$ potassium dihydrogen phosphate $\left(\mathrm{KH}_{2}\right.$ $\mathrm{PO}_{4}$ ), adjusted to different $\mathrm{pHs}$ with phosphoric acid $\left(\mathrm{H}_{3} \mathrm{PO}_{4}\right) ; \mathrm{H}_{2} \mathrm{SO}_{4}(0.02 \mathrm{~N}$ to $0.005 \mathrm{~N})$ prepared by diluting reagent grade sulfuric acid with MilliQ water (Millipore).

The solvents used for the mobile phases were of HPLC grade and were employed as supplied.

Analytical grade organic acids without further purification were used as standards: malic, quinic, lactic, citric, succinic and shikimic acids were purchased from Sigma (St. Louis, MO, USA) and Merck (Darmstadt, FRG).

Apple extracts were prepared as described by Richmond et al., [12] with some modifications in order to ensure the extraction of other components present in apples [13]. Before injection, apple extracts, apple juice and cider were filtered through a $0.45 \mu \mathrm{m}$ Millex membrane to remove impurities that might be present. The carbonated ciders were first degassed for five minutes in an uitrasonic bath. Complete triplicate analyses were performed on all samples to enable calculation of average deviations which were useful as a means of measuring the extraction and chromatographic reproducibility.

\section{Results and Discussion}

Standards of the acids were prepared individually in ultra pure water and chromatographed separately in order to determine the retention time for each acid. The acids were then chromatographed as a mixture and chromatographic conditions were altered to maximize peak resolution.

Three different columns were used for the analysis. One was packed with an Interaction cation exchange resin in the hydrogen form. The separation mechanism is largely by Donnan exclusion of the acids and hydrophobic interactions and steric effects also influence retention. Acids of intermediate strength (such as most carboxylic acids) are partially ionized. The degree of dissociation, and therefore retention, can be controlled by adjusting the $\mathrm{pH}$ of the acid eluent.
On resin columns operated in the hydrogen form, fructose and malic acid can co-elute, which is a potential problem in the analysis of organic acids in apple juice unless detection at a longer wavelength (220 to $230 \mathrm{~nm}$ ) is used.

This column, $10 \mathrm{~N}-300$, operated at elevated temperatures $\left(45^{\circ} \mathrm{C}-90^{\circ} \mathrm{C}\right)$ using dilute sulphuric acid $(0.005 \mathrm{~N}-0.02 \mathrm{~N})$ as eluent at flow rates of $0.3-0.4 \mathrm{ml} / \mathrm{min}$ with UV detection at $206 \mathrm{~nm}$.

Initial separation was performed at $45^{\circ} \mathrm{C}$ with $0.005 \mathrm{~N}$ $\mathrm{H}_{2} \mathrm{SO}_{4}$ mobile phase and $0.3 \mathrm{ml} / \mathrm{min}$ flow rate. The chromatogram showed poor separations of components with a large overlapping of malic and quinic acids and co-elution of succinic, shikimic and lactic acids. Changes in chromatographic conditions (acid concentration ineluent, increasing column temperture to $90^{\circ} \mathrm{C}$ and increasing eluent flow-rate) failed to improve the resolution. An aqueous standard chromatogram containing a mixture of organic acids is illustrated in Fig. 1. Another column used in this separation was Spherisorb $\mathrm{NH}_{2}$ with buffer solutions of $\mathrm{KH}_{2} \mathrm{PO}_{4} / \mathrm{H}_{3} \mathrm{PO}_{4}$ as mobile phase. As a result of optimization studies $(\mathrm{pH}$ from 3.0 to 4.5 ; ionic strength from $10^{-2} \mathrm{M}$ to $7.510^{-2} \mathrm{M}$; and temperature from $15^{\circ} \mathrm{C}$ to $55^{\circ} \mathrm{C}$ ) the experimental conditions were fixed as: $\mathrm{pH}=4.25$; ionic strength $7.510^{-2} \mathrm{M}$; temperature $25^{\circ} \mathrm{C}$ and flow rate $1 \mathrm{ml} / \mathrm{min}$. Fig. 2 shows the results obtained with this column. As can be seen, overlapping of the quinic and lactic acid appears and the succinic acid is not well resolved. Furthermore, the later peaks show a great broadening which makes quantification difficult. Furthermore, this stationary phase showed a slight solubility in the mobile phase, resulting in a reduced stability. Therefore, the use of an RP-18 bonded phase that was more stable and withstood buffer salt changes and high temperature without suffering a loss of column efficiency was considered.

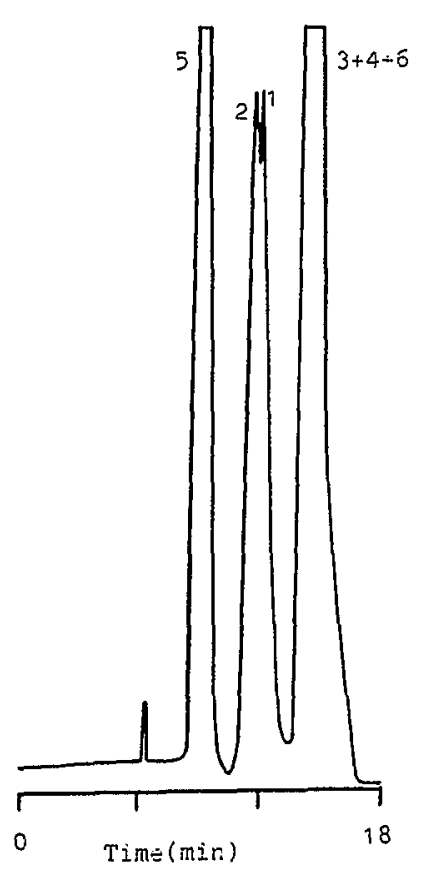

Fig. 1:

Chromatogram of a standard organic acid mixture. Column: $1 \mathrm{ON}-300$ $200 \times 7.8 \mathrm{~mm}$ i.d. Mobile phase: $\mathrm{H}_{2} \mathrm{SO}_{4} 0.01 \mathrm{~N}$; flow rate $0.4 \mathrm{ml} / \mathrm{min}$; temperature: $55^{\circ} \mathrm{C} .1=$ quinic acid; $2=$ malic acid; $3=$ shikimic acid; 4 = lactic acid; 5 = citric acid; $6=$ succinic acid. 
The relative retention time of organic acids by reversephase HPLC is critically dependent on $\mathrm{pH}$ in the $\mathrm{pH} 2-3$ range. Although this means that $\mathrm{pH}$ control and buffering capacity for a given separation must be closely controlled, it does also offer the potential for optimising separation according to the sample being analysed.

Conditions were optimized by changing one parameter at a time while keeping the others constant in order to improve the separation. As a result of the optimization studied the operating conditions for the HPLC system, using an RP-18 column, were as follows: flow rate $0.5 \mathrm{ml} / \mathrm{min} ; \mathrm{pH} \mathrm{2.25}$; temperature $25^{\circ} \mathrm{C}$ and ionic strength $10^{-2} \mathrm{M}$.

The detection wavelength was $206 \mathrm{~nm}$. This affords the possibility of detecting the succinic acid (which contributes to sensorial characteristics of ciders) from the first stages of fermentation because as can be seen in the isogram (Fig. 3) the greatest sensitivity was observed here. Fig. 4 shows the results obtained with this column. In comparison with the previous columns good resolution was obtained for all the acids studied, in addition to acetic acid, allowing its quantification to be performed also.

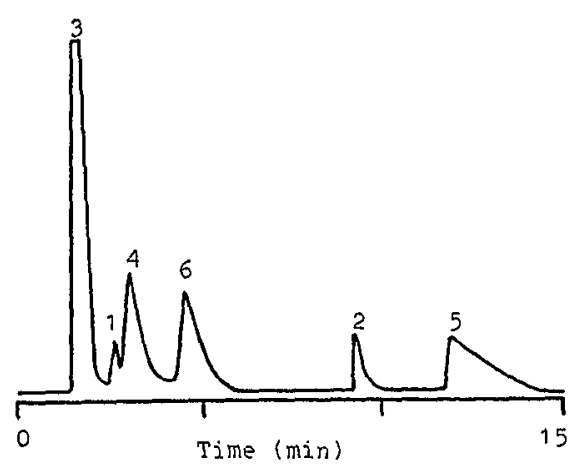

Fig. 2:

Chromatogram of a standard organic acid mixture. Column: Spherisorb $\mathrm{NH} 2,250 \times 4 \mathrm{~mm}$ i.d. Mobile phase: $\mathrm{KH}_{2} \mathrm{PO}_{4} / \mathrm{H}_{3} \mathrm{PO}_{4} 0.075 \mathrm{M}$; pH 4.25; flow rate: $1 \mathrm{ml} / \mathrm{min}$; temperature $25^{\circ} \mathrm{C} .1=$ quinic acid; $2=$ malic acid; $\mathbf{3}=$ shikimic acid; $\mathbf{4}=$ lactic acid; $\mathbf{5}=$ citric acid; $\mathbf{6}=$ succinic acid.

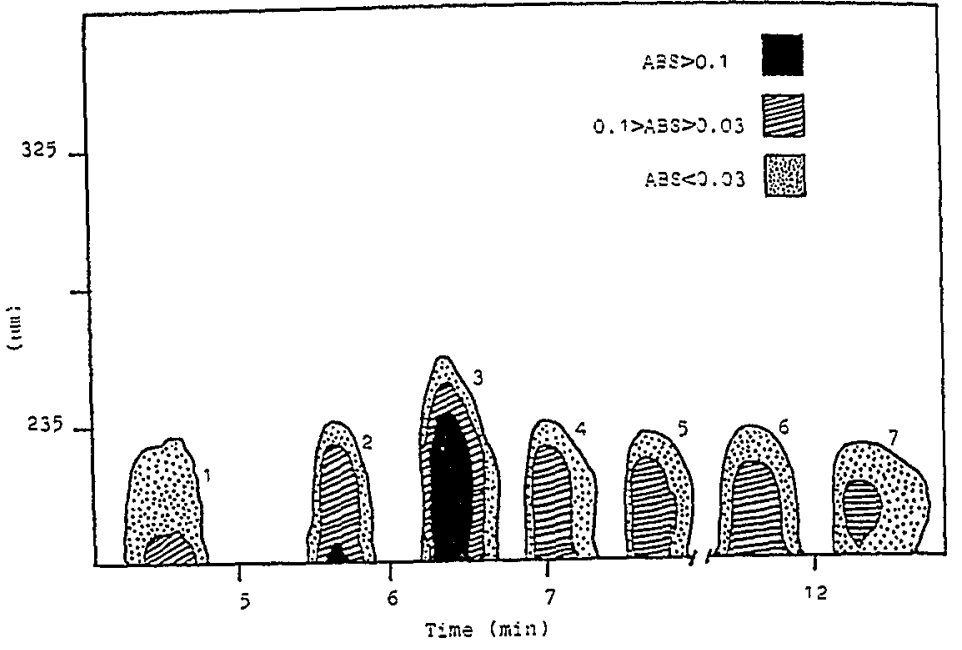

Fig. 3:

Isogram of organic acids, showing the isoabsorbance contours plotted in the wavelegth-time plane.

Column: Spherisorb ODS-2 $250 \times 4 \mathrm{~mm}$ i.d. Mobile phase: $0.01 \mathrm{M}$ potassium dihydrogen phosphate $\left(\mathrm{KH}_{2} \mathrm{PO}_{4}\right) / \mathrm{H}_{3} \mathrm{PO}_{4}, \mathrm{pH} 2.25$; flow rate: $0.5 \mathrm{ml} / \mathrm{min}$; temperature $25^{\circ} \mathrm{C} .1=$ quinic acid; $2=$ malic acid; $\mathbf{3}=$ shikimic acid; $\mathbf{4}=$ lactic acid; $\mathbf{5}=$ acetic acid; $\mathbf{6}=$ citric acid; $7=$ succinic acid.

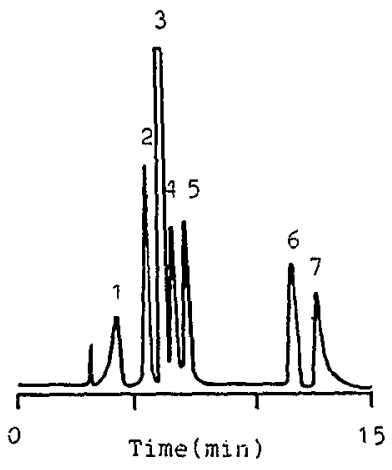

Fig. 4:

Chromatogram of a standard organic acid mixture. Acids and chromatographic conditions as in Fig. 3.

Table 1. Evolution of organic acids in apples during the last three months of ripening.

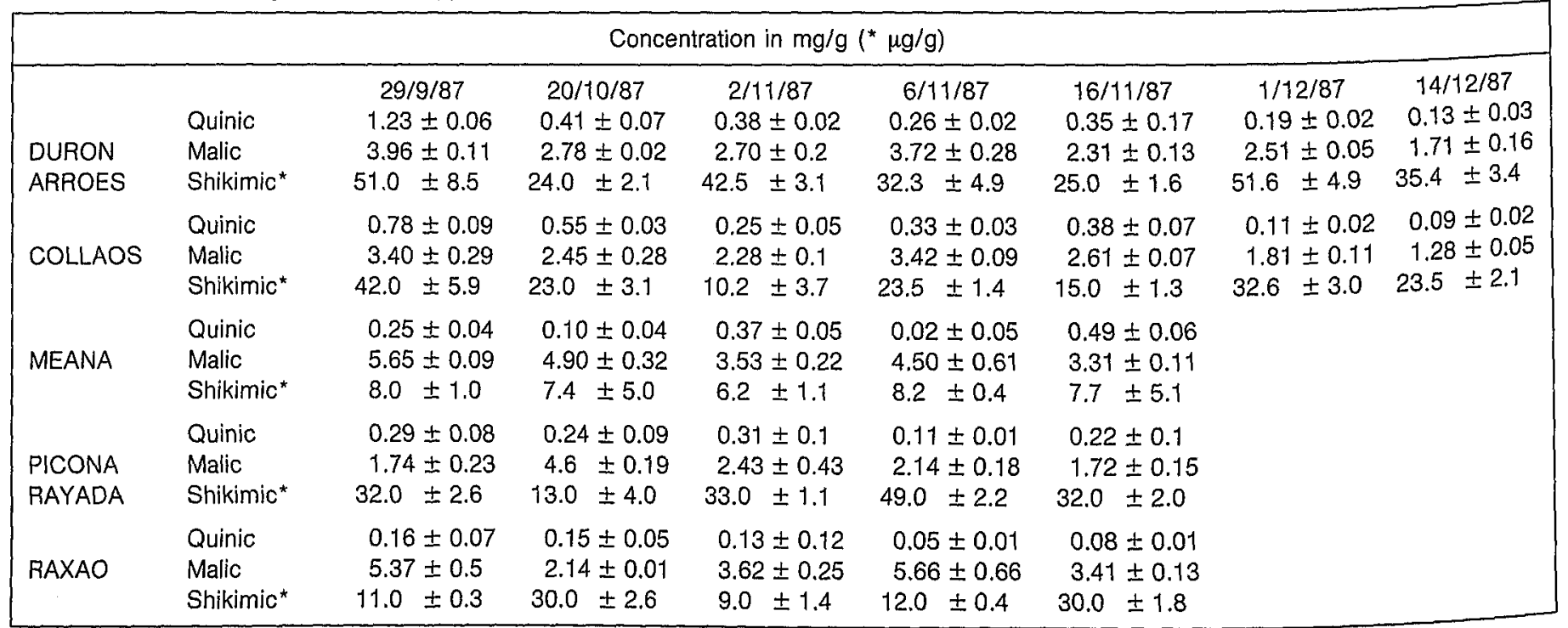




\section{Quantification and Recovery}

A typical chromatogram for an apple extract using the operating conditions specified is shown in Fig. 5. The resolution obtained for all acids allowed their quantification to be carried out. The quantification of the acids was achieved by using the external standard method. The calibration curve data were generated by repeated injections of a fixed volume, $20 \mu$, of standard solutions of acids covering a broad concentration range. The resulting peak areas were determined, plotted against concentration and stored in the data module. Injection volumes of $20 \mu \mathrm{l}$ were employed for all quantitative evaluations and the amount of acids was directly obtained from the data module. A recalibration was regularly performed with standard solutions to obtain new response factors. Typical results and standard deviations of triplicate determinations for five varieties of apples extracts in five stages of maturity are presented in Table I and Fig. 6. It can be seen that the concentration of malic acid generally shows a steady decrease although with some variaties of apples it reaches a maximum and then decreases. The quinic acid decreases quickly in the first phases of ripening, and the shikimic acid - always present in very small quantities - undergoes small changes. It was not possible to determine the citric acid because this acid was present in small concentration and it was only detected when the malic acid was present in greater concentration, confirming that both acids have a similar evolutive process [14]. Results and standard deviations of triplicate determinations for two apple juices in several stages of fermentation are presented in

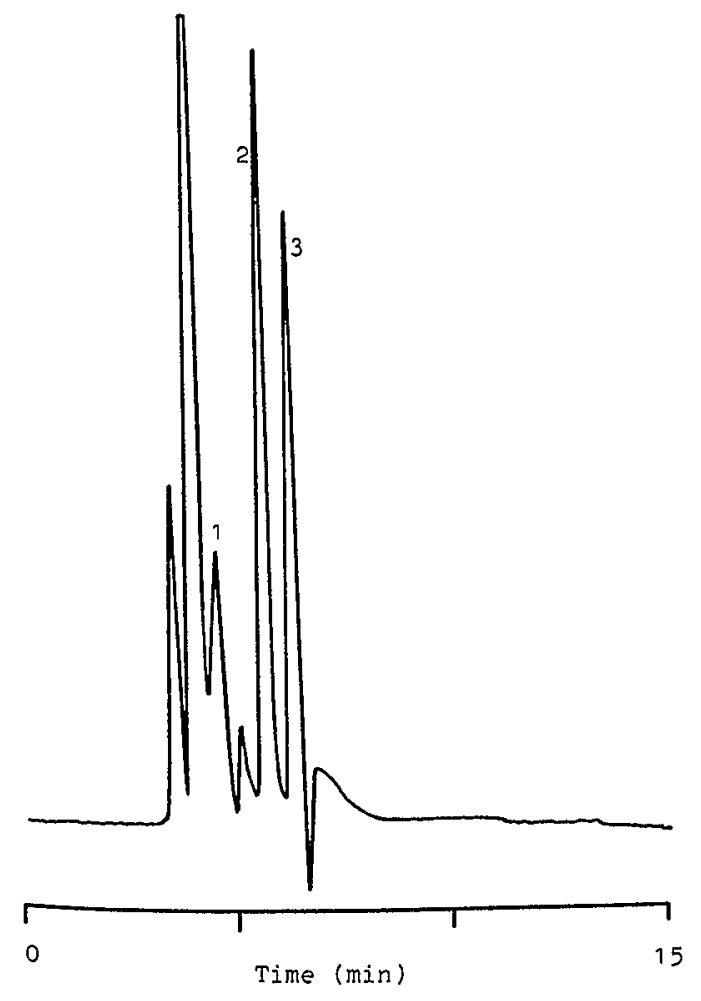

Fig. 5:

Typical chromatogram of organic acids in an apple extract. Columns and chromatographic conditions as in Fig. 3. $1=$ quinic acid; 2 = malic acid; $\mathbf{3}=$ shikimic acid.
Table II and Fig. 7. During the course of fermentation the organic acids undergo a number of changes due to bacterial activity, which are controlled by $\mathrm{pH}$ value. It can be seen that the malic and citric acid concentration decreases, while the lactic and succinic acid concentration increases.

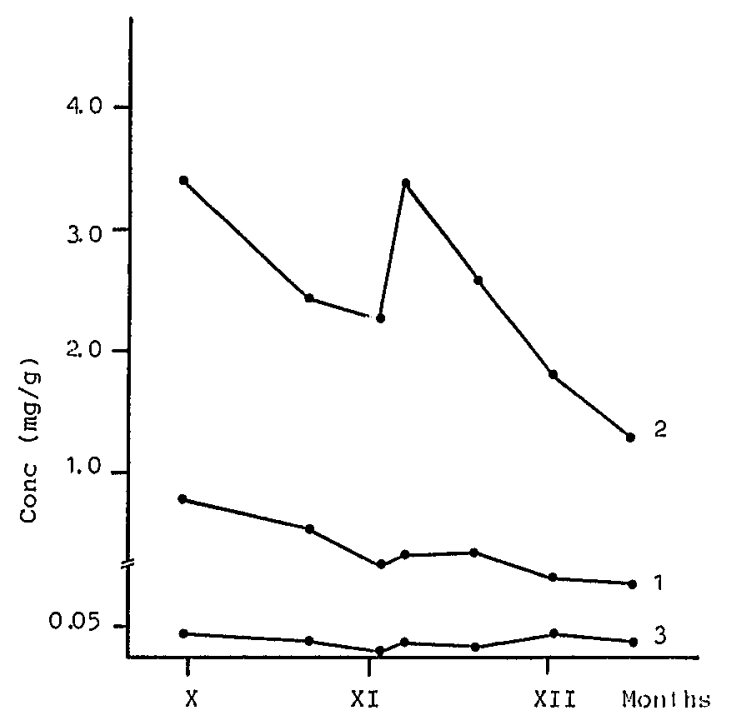

Fig. 6:

Evolution of organic acids in "Collaos" apples during the last three months of ripening. Column and chromatographic conditions as in Fig. 3.

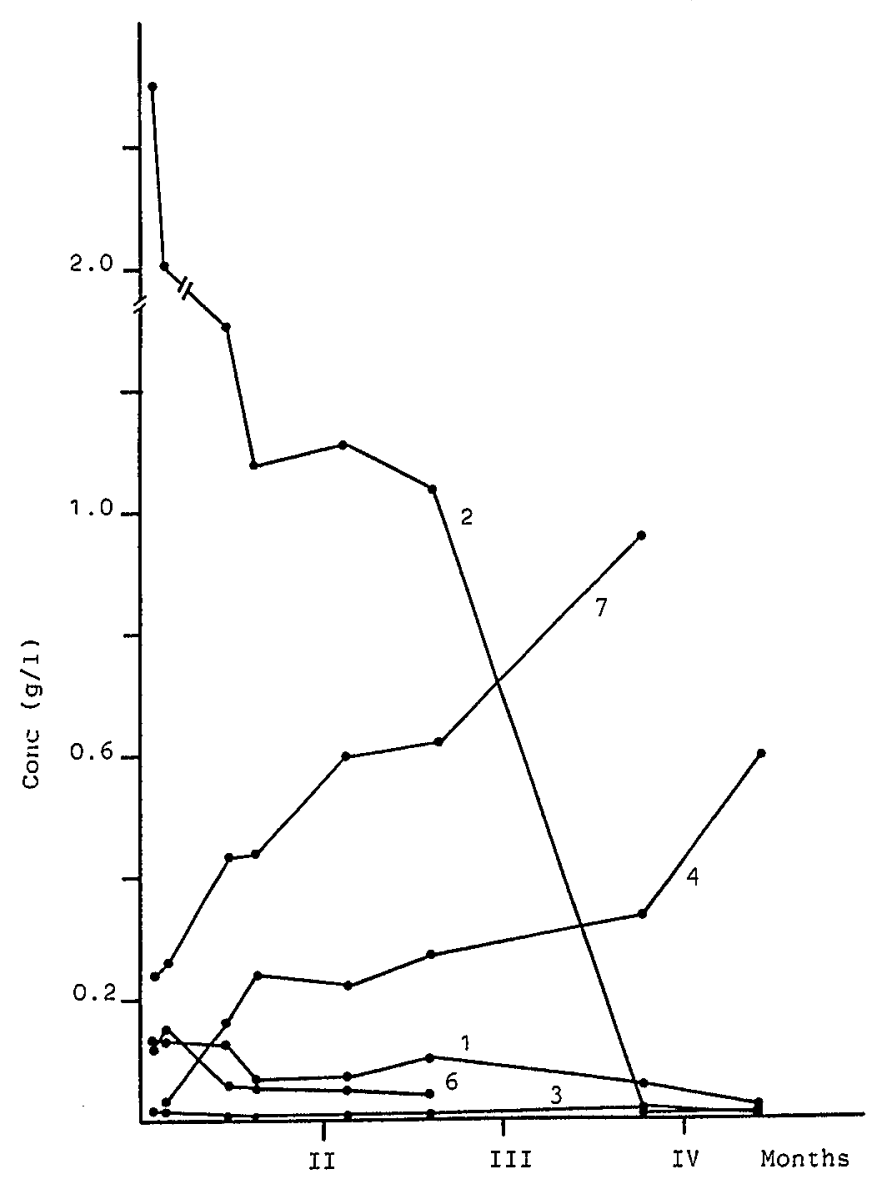

Fig. 7:

Evolution of organic acids in apple juice during three months of fermentation. Column and chromatographic conditions as in Fig. 3. 
Table 2. Evolution of organic acids in apple juices during three months of fermentation.

\begin{tabular}{|c|c|c|c|c|c|c|c|}
\hline & DATE & Quinic & Malic & Shikimic & Lactic & Citric & Succinic \\
\hline \multirow{7}{*}{ 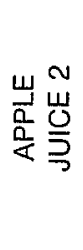 } & $2 / 1 / 88$ & $0.1278 \pm 0.009$ & $2.3030 \pm 0.023$ & $0.0145 \pm 0.0006$ & - & $0.1221 \pm 0.012$ & $0.2431 \pm 0.051$ \\
\hline & $4 / 1 / 88$ & $0.1327 \pm 0.048$ & $2.0999 \pm 0.37$ & $0.0144 \pm 0.0013$ & $0.0257 \pm 0.010$ & $0.1528 \pm 0.017$ & $0.2593 \pm 0.073$ \\
\hline & $14 / 1 / 88$ & $0.1253 \pm 0.020$ & $1.3192 \pm 0.44$ & $0.0083 \pm 0.0004$ & $0.1652 \pm 0.022$ & $0.0591 \pm 0.003$ & $0.4350 \pm 0.027$ \\
\hline & $19 / 1 / 88$ & $0.0645 \pm 0.011$ & $1.0801 \pm 0.11$ & $0.0038 \pm 0.0002$ & $0.2391 \pm 0.069$ & $0.0574 \pm 0.007$ & $0.4405 \pm 0.043$ \\
\hline & $4 / 2 / 88$ & $0.0724 \pm 0.006$ & $1.1194 \pm 0.092$ & $0.0049 \pm 0.0003$ & $0.2268 \pm 0.031$ & $0.0518 \pm 0.015$ & $0.6035 \pm 0.001$ \\
\hline & $18 / 2 / 88$ & $0.1014 \pm 0.005$ & $1.0399 \pm 0.100$ & $0.0062 \pm 0.0003$ & $0.2690 \pm 0.078$ & $0.0390 \pm 0.021$ & $0.6209 \pm 0.049$ \\
\hline & $23 / 3 / 88$ & $0.0549 \pm 0.006$ & $0.0116 \pm 0.002$ & $0.0221 \pm 0.0001$ & $0.3349 \pm 0.043$ & - & $0.9606 \pm 0.244$ \\
\hline \multirow{5}{*}{ 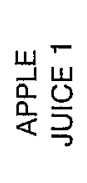 } & $14 /$ & 0.0 & $0.9809 \pm$ & $0.0078 \pm$ & $0.0654 \pm 0.017$ & $0.0362 \pm 0.007$ & $0.5108 \pm 0.084$ \\
\hline & $19 / 1 / 88$ & $0.1157 \pm 0.009$ & $0.7817 \pm 0.015$ & $0.0138 \pm 0.0010$ & $0.1127 \pm 0.004$ & $0.0688 \pm 0.004$ & $0.6970 \pm 0.115$ \\
\hline & $4 / 2 / 88$ & $0.1470 \pm 0.011$ & $0.0498 \pm 0.001$ & $0.0240 \pm 0.0010$ & $0.1506 \pm 0.015$ & $0.0584 \pm 0.009$ & $0.7359 \pm 0.119$ \\
\hline & $18 / 2 / 88$ & $0.1201 \pm 0.017$ & $0.0193 \pm 0.002$ & $0.0239 \pm 0.0004$ & $0.1941 \pm 0.012$ & $0.0201 \pm 0.005$ & $0.7721 \pm 0.160$ \\
\hline & $23 / 3 / 88$ & $0.1533 \pm 0.019$ & $0.0237 \pm 0.001$ & $0.0247 \pm 0.0020$ & $0.3769 \pm 0.051$ & - & $0.9707 \pm 0.174$ \\
\hline
\end{tabular}

In order to determine the accuracy of the method, recovery studies were carried out. Known amounts of malic, citric, succinic, quinic, lactic and shikimic acids were added to a variety of samples and the resulting spiked samples were subjected to the entire analytical sequence. Three different concentration levels of spiked acids were analyzed. The recoveries were calculated based on the difference between the total amount determined in the spiked samples and the amount observed in the non-spiked samples. Complete duplicate analyses were performed.

The recoveries of organic acids added to apple extracts and apple juices were over $100 \%$ for all acids.

\section{Conclusions}

The method reported here appears to be a useful and versatile procedure for research on the evolution of organic acids in apple extracts, apple juices and ciders. It does not necessitate long and tedious clean-up, extraction or isolation operations. The procedure is rapid, simple and economical. For juices, only a sample dilution is needed and analysis time is reduced to minutes at most. The proposed method of analysis can probably be applied to other foods and beverages.

\section{Acknowledgement}

This work was financially supported by the Comision Asesora para la Investigacion Cientifica y Téchnica (CAICYT, PA 310/85)

\section{References}

[1] J.G. Carr, G.C. Whiting, J. Appl. Bac., 34, 81 (1971).

[2] M.A. Harmon, H.N. Doelle, J. Chromatogr., 42, 157 (1969).

[3] R. Anderson, B. Hedlund, Z. Lebensm. Unters. Forsch., 176 440 (1983).

[4] S.H. Ashoor, J. Welty, J. Chromatogr., 287, 452 (1984).

[5] S.H. Ashoor, M.J. Knox, J. Chromatogr., 299, 288 (1984).

[6] R.J. Bushway, J.L. Bureau, D.F. McGann, J. Food Sci., 49, 75 (1984).

[7] J.P. Goiffon, A. Blachere, C. Reminiac, Analusis, 13, 218 (1985).

[8] P. Pfeiffer, F. Radler, Z. Lebensm. Unters. Forsch., 181, 24 (1985).

[9] R. Schwarzenbach, J. Chromatogr., 251, 339 (1982).

[10] E. Mentasti, M.C. Genaro, C. Sarzanini, C. Baiochi, M. Savigliano, J. Chromatogr., 322, 177 (1985).

[11] J. Ribereau-Gayon et al. "Traite d'oenologie. Sciences et techniques du vin", Dunod, Paris, 1975, pp. 526-530.

[12] M.L. Richmond, S.C.C. Brandao, J.I. Gray, P. Markakis, C.M. Stine, J. Agric. Food Chem., 29, 4 (1981).

[13] D. Blanco, M.D. Gutiérrez, J. J. Mangas, A. Noval, Chromatographia, 25, 701 (1988).

[14] E. Primo Yúfera, "Quimica Agricola. III. Alimentos", Alhambra, Madrid, 1979, pág. 254.

Received: Aug. 3, 1988 Accepted: Aug. 23, 1988 